\title{
Art-Based Educational Research to Generate a Practice Based Approach
}

\author{
Suzan Duygu Bedir Erişti \\ Anadolu Üniversitesi \\ sdbedir@anadolu.edu.tr
}

\begin{abstract}
Arts-based research was born in an academic context where the arts and research unite. The departing point of today's art-based educational research studies is to bring a more in-depth and critical thought. As a growing field of interest, art-based research is becoming an effective approach in every step of the research practice. The relationship between art-based research and practice provides a fertile ground for new and extraordinary approaches to the research phenomenon. That's why in liberal arts and educational research, literature on theoretical and practical dimensions of art-based research becomes essential. Such literature directs its concentration toward introducing artists and social scientists to various approaches of art-based research while making it possible, for them, to apply these approaches and reach original results. These approaches give chance to the researcher to arrange the research process, participants, and other elements of the researched phenomenon in different ways utilizing different angles. In other words, especially in educational contexts, art-based research approaches bring new possibilities for detailed and deep interpretation with new points of view and a new understanding of the nature of research. In this respect, art-based educational research has emerged as a rising field of study that provides new space for effective interaction and communication among researchers, education professionals, and artists. The researcher conducting art-based research approaches has to utilize relationships between multiple disciplines creating new ways of seeing.
\end{abstract}

Keywords: Art based research, Art based educational research, Research process, Visual research methods, A/r/tography 


\section{Introduction}

Art-based research approaches in educational process started in 1970s (Eisner, 1976; Greene, 1975; Grumet, 1978; Vallance, 1977). The purpose of art-based approaches is to integrate aesthetic concern into research process considering various components. The reflections of aesthetic and art-based forms on educational research were started to be used in 1990s with various approaches such as narration based works, autobiography, art and movement, exploratory and reader theatre, multimedia hyper-text, visual arts, photograph, music, poem, creative interpretation, creative writing, drawing, film, dance, music, visual reading, visual formation, collage and cartoon based approaches, the approaches based on digital art and application, reflective drawing. The integration of art-based approaches into research process has helped researchers gain meaning (Sullivan, 2010). With the integration of art-based research approaches into educational researches, the amount of art-based educational research has started to become more common. In an art-based research process, majority of researchers have the chance to investigate some approaches in educational settings based on artistic data (Denzin \& Lincoln, 2005; Cole \& Knowles, 2001; Barone \& Eisner, 1997). This helps researchers investigate how education process is, what meanings it has, what learning takes place and the effectiveness of learning in educational purpose (Finley, 2005). Considering an approach relating research and, perceptions of researchers and research participants related to various cases are revealed under the light of their own impressions (Denzin \& Lincoln, 2005; Eisner, 2002). This leads to the planning of a more interactive research process (Denzin \& Lincoln, 2005).

Art-based research process actually offers researchers a reality of which they are unaware. This reality is the visual reality which is investigated through meanings based on researchers and participants' symbolic and image based meanings. Visual reality can be used as a means of gathering data as well as being a tool for analysis and explanation. Visuality contributes new 
dimensions to research processes different from actually existing ones (Cahnmann, Taylor and Siegesmund, 2008). Art based research approach can be suggested to broaden researchers' perspectives, perceptions and knowledge (Barone, 2008). Art-based researches focuses on generate knowledge rather than reveal it.

The aim of the research was to examine the art based educational research through an effective research process. The discussion of research serves the determination of the reflections of the art based educational research approach on educational research and to associate art based research approach with educational research process considering the aim of the content. Art based approaches in educational settings offer a practice based approach integrated within artistic dimensions. There are some specific goals presented as:

- to provide an overview and analysis of art based educational research context related to the research process.

- to identify any significant issues related to art based educational research

- to recommend ways to implement and use art based educational research in research environments to construct multiple skilled research process.

- to examine the relationship of art based educational research with the research process.

- to identify how art based educational research should be effective on research process and which further development could be suggested for an effective research process based on art.

\section{Methodology}

First, the conceptual framework was used in the study to reflect the art based educational research through the aim of the chapter. A brief discussion outlining the perspectives of the concepts guiding the research is outlined. At the next step, components of chapter and the relationships between the determined concepts were discussed. 


\section{A Review of Related Literature}

Art-based educational researches cover interpreting a research process based on cooporations of researchers, art and research and looking for answers to the research questions. The common points of the approaches which are based on the integration of art and education into the research process is that they offer researchers a ground to build a more interactive research process. That is because art and education complement and support one another in art-based education research and they contribute their perspectives which are considered to be their reflections on research process. Art-based educational research process adopts an application based approach in a multi systematic structure, and it establishes meaningful experiences combining theory and interactive, critical, natural, cognitive and artistic applications. In such a process, it is very significant to give the meaning to the experiences of researchers, teachers and participants. With this regards, an art-based educational researches help build a relationship among artists, researchers and teachers in educational process.

Art-based research approaches are used with various alternatives such as "Approaches based on Artistic Effect", "Art-based questioning", "School Art Interaction" and "Art Approach based on research". "Art-based Educational Research" is the most commonly used approach nowadays.

Art-based educational research has been a growing application field where art and research academically unite (Cahnmann-Taylor \& Siegesmund, 2008, 2008). It is very significant to reveal critical reflections which are considered to be the crossing point of art and research nowadays. The relationship between art-based research and applications and the fact that this relationship brings about unusual approaches to research process are considered to be unavoidable. A theoretical and applicational art-oriented literature in the field of social sciences and education has been attracting much attention in recent years. (Cahnmann-Taylor \& 
Siegesmund, 2008; Leavy, 2009; Springgay, Irwin, et al, 2008; Sullivan, 2010; Barone \& Eisner, 2012). The most basic point that these researches focus is that the fact that educationalists and social scientists and artists meet with the art-based research approaches, and that they use them in research processes, leads to the establishment of extremely authentic studies because art-based approaches offer researchers the chance to gain a different perspective in association with the components of research process.

Art-based research process has the following movements such as, definition of uncertainty, formation of semantic conceptual language, putting forth relational and critical reflections, developing empathizing skills, including researcher's personal approaches in the research process as a gain, using aesthetic concerns to interiorize for both researchers and participants and concretizing a truth beyond the truthiness (Cahnmann-Taylor \& Siegesmund, 2008).

Art-based education researches reveal the role of art associated with education. The conceptual and critical quality of art which is intended to define learning/teaching processes result from the fact that artistic production is capable of meeting some conditions such as planning, developing. Personal interpretations can only reach the level of originality with the help of artistic and art-based research approach. The approach of Art-based educational research helps education researches broaden their conceptual border lines. Virtual based education researches help both researchers and participants' inner world reveal their creative perspectives through alternative visions. Researchers and participants are aware of what is happening in the research process and they are productive (Sullivan, 2010).

Art-based research approaches offer researchers with the opportunities to monitor art, record it, define it, put forth the trueness and drawing in-depth meanings as well as helping gain some competencies such as associating the above mentioned facilities, organizing them and restructuring. 
Art-based approaches help interpret the problem through a more in-depth and sophisticated understanding and design a more qualified research process as well as putting forth the already existing situation considering the research questions. In an art-based research approach, what is important for a researcher is to know well what and how to obtain something and to know how they should structure the knowledge and what possibilities they need to reveal. The reflections of art-based research methods can be seen as a special and effective evaluation or data collection approach in the field of social sciences. The effective use of art-based data in research process is closely related to what extend the approach used in the research is related to the research question. Art-based research approach helps researchers question what they are dealing with, or design a process which helps interpret and report the story of the research process. Art-based approaches generate knowledge.

However, what is important here is to decide for what purpose it will be used (Sullivan, 2010). Because revealing some shared characteristics of research making in an art-based educational research process helps both participants and researchers question their personal competencies from a realistic perspective ignoring some personal limitations, it also helps them interpret teaching related differences and similarities, points out cultural and generational differences, evaluates teaching related experiences with a critical perspective, all of which are considered to be among the approaches used to concretize the nature of the study in its natural setting.

Besides, an art-based education research offers opportunities to use some approaches under the control of the participants. With personal perspective, research and contextual relationships are investigated in depth and this does not disturb participants (Irwin, 2004).

The chances for the participants to empathize the research process can be more frequently encountered in art-based educational researches. Internalizing the research in an educational research setting clearly helps researchers see how participants physically and mentally position 
themselves in this process (Irwin, 2004). In other words, as participants define their roles in the research, they both empathize and use their creativity potential, which makes the research a rich one. Self-expressions of participants in an art-based educational research, their offering research related experiences and being responsible for their experience are all considered to be clear signals of empathy relationships with the researcher. In other words, the facilities offered to the participants in the research through art-based approaches and the artistic meanings emerging as a consequence of that contributes to the direct determination of their personal levels related to the purpose of the research. That is to say that art-based approaches encourage participants to reveal and examine their investigative identities (Leavy, 2009). Because research experience specifically energizes the participants of educational researches, encourages them for detailed investigation of learning opportunities. Besides, it also builds close relationships between real life and the purpose of the study.

The approach of art-based education research focuses on keeping participants active in the interaction between participant and researcher, on meaningful experiences, obtaining sustainable and transferable gains in real life, and most significantly on reproduction of research related data through learning and teaching and sharing of them (Cahnmann-Taylor \& Siegesmund, 2008). Therefore, art-based approaches help participants associate and interpret the research related products or research related concepts and research process and thus help them gain creativity.

In the use of art-based research approaches for educational processes, it is not an aim for researchers to evaluate aesthetic approaches. It is a well-defined research process presented by art-based approaches to educational researches. Art-based approaches help both researchers, the participants of the researches, and some other factors having effect in the research process interpret their inner world in a more detailed way. No matter if it is narration or dramatic situation or poem, the most basic principle underlying all approaches for researchers to be able 
to see the research process and participants in a more detailed way than that which cannot be seen under normal conditions (Barone and Eisner, 2012). The incline to the art-based methods in teaching, learning and research processes can be considered to be a reflection of the changes in modern day cognition. Systematic approach, relational thinking, being many-sided and the facilities used for structuring both educational and research strategy and art-based educational researches are all counted among the modern day inclination. Art-based research approaches offer the opportunity for researcher to interpret educational research process, participants' attitudes and the nature of the research in depth.

Educational researches mostly experience loss of confidence when they lack of coming to a conclusion using concrete indicators because these methods seem to be irrelevant to real life practices. In such cases, the outcomes of the study carried out are away from being effective and playing a guiding role (Levin and O'Donnell, 1999). In research process, researchers need more concrete, clearer and more observable research approaches.

When we consider today's educational researches, it is clear that there is an urgent need for some new research conditions in which critical perspectives and research focus can be more clearly put forth leaving the methods aside which are known to lack of adequate data collection.

The changes and transformations in up-to-date research approaches have led to restructuring of research process. Based on these transformations, research making competencies has become a necessity to be questioned and restructured with regards to both researchers, the methods and approaches used in the study. It is very important for future research.

"Interpreting the research process through different disciplines and the approaches depending on these disciplines will contribute a lot to the research process and also help researchers be more competent and interpret research process through various alternatives. With this regard, it 
Anadolu Journal of Educational Sciences International, Art Education Special Issue, November 2015

is very important for the educational programs in which new research approaches and perspectives are effectively used to have appropriate content and practices

\section{Art-based Educational Researches}

It can be suggested that art based approaches reflect on educational researches as a new turning point. The reflections of art based research approach on research process can be stated as follows;

- Research subject have reached a relational and ongoing structure.

- Cultural and characteristic effects have started to play more effective roles in research processes.

- Multidimensional, having universal characteristics, being multicultural and universal communication were rehandled together with local identities and reinterpreted.

- As cultural identities are subjects to reinterpret as a consequence of technological developments, the components of research process should be evaluated in this regard.

- Educational research process has changed its role with entertainment concept and it has transformed into a structure in which participants could interpret what they learned from the process in a more meaningful way.

- There is an increasing need for an in-depth evaluation of truth and trueness in an educational research process.

When the contribution of educational research to the structuring, developing and transforming and renewing of educational process is considered, the responsibility for the participant students need to be revised from the beginning. In art based research process, the approaches aiming to find out the best ways for educational researches to come up with answers to the research problem has come to the forefront rather than obtaining the relevant data. Changing a 
behavior in its natural context, interpreting and giving the meaning to the teaching item through different structuring models, obtaining the research through unusual and creative ways.

The points which need to be paid attention within the frame of art based research process are:

- Considering research subjects, participants, investigative, connective and discriminating items in a research process,

- Ignoring that the sources of the knowledge obtained in a research process need to be discussed in detail in an effective way,

- Showing a tendency to obtaining the research subject directly and within its natural context,

- Keeping in mind that direct experiences which reveal the core of the research in a research process, should always be considered,

- Paying a special attention to not letting the data obtain in the research lose its authenticity.

- Considering the variability of the reflections of social, cultural, historical contexts which are considered to be the starting points of research problems,

- Adapting a research approach based on participation and introspection with regards to researcher and participants,

- Considering the fact that researchers and participants have a multidimensional, variable social structuring in a research process (Badmington, 2000; Alvesson \& Skoldberg, 2000). 
Art-based research process investigates in-depth the research trueness by its nature, offers the opportunities to obtain data, offers opportunities to use different methods of data collection. It also helps researchers commit to the research process in a multidimensional way. Art-based approaches restructure researches as well as portraying and interpreting research process, and it also facilitates redefinition of participants, researchers and research process. In this defining process, artistic forms, expressions, points of views or manifestations all turn out to be the tools serving the aim of the research. It can be suggested that art-based approaches offer researchers the opportunities to use their creativity in the research process. As researchers are restructuring the research with a new creativity, they also contribute to research process with different art forms and ways of expressions. Thus, the above mentioned process turns out to be a case in which individuals, symbols and perspective are added into the research process, in which innovative, instigator, accelerator, self-consciousness raising, sensitive approaches are promised (Diamond \& Mullen, 1999). There are some differences and structuring the research on these differences adds richness to research process and offers researchers the opportunity to investigate identities in detail. At this point, art-based approaches reflect differences on research process and thus researchers can handle the research process to focus on the core of the research.

\section{The reflections of Art-based research approaches in Educational researches}

The reflections of art-based research approaches on research process can be examined with regards to researchers, participants and research process to generate knowledge.

\section{Reflections on Researchers}

Art-based research approach helps researchers develop an investigative, authentic, creative and in-depth perspective. It also contributes to researchers' competencies and motivation from 
different perspectives in related to subject and literature, and it also helps them use their creativity power effectively in research process. Art-based educational research approaches contribute to researchers' vision formation regarding to different context. The knowledge that researchers have related to educational sciences and art education offer them a different perspective together with a multidimensional perspective. Art-based approaches offer the opportunity to reevaluate educational research processes and to evaluate the target field through artistic practices beyond the trueness. Researchers can reflect both their pedagogical and investigative identities in educational research processes (Irwin \& O’Donoghue, 2012). Thus, researchers have the opportunity to have a more qualified reflection experience in the research process.

\section{Reflections on participants}

Art-based educational research approaches help participants better structure the components of educational researches pedagogically, which is the subject of the study. Research participants can clearly express where participants are positioned in the study. The research participants could clearly state at which point of the research they were positioned. The contribution of the participants in the research process is at high level as it is highly possible for them to draw deeper semantic conclusions. Participants attribute deeper meanings and have the opportunity to put forth their significance in the research process through different ways. It is possible to draw conclusions about how important the research is for participants and to adapt a multidimensional perspective with regards to the meanings attributed. The participants pedagogically experiencing an effective and meaningful research experience may be more willing to participate in the process (Dixon \& Senior, 2010). Research process turns out to be a case in which the process starts to be associated with various perspectives with the help of artbased approaches, in which sense-making is deeper (Irwin \& O Donoghue, 2012). Art-based 
research approaches increase the chances for participants to be multidimensional, investigative, to be highlighter, to have a tendency for personal commitment, to be responsible for something during the participation period, to have an interdisciplinary perspective, to adapt creative approaches and reflective experiences. With this regard, it makes the research process authentic. As participants are expressing themselves, they experience an in-depth reflection process. Participants play active roles in the research process as well as being reflective, and they can express themselves as creative individuals and develop new competencies with regards to artistic articulation (Irwin \& O’Donoghue, 2012). Participants show active participation in educational researches at observation, questioning, analyzing and interpretation, and with this regard, they can perform some competencies (Dixon \& Senior, 2010).

\section{Reflections on Research Process}

It can be suggested that art-based educational research approach possess some applications which help research process sustain more effectively and authentically. It contributes to the sustainability as it offers some facilities satisfying participants and researchers. Besides, the investigation of the process by its nature in a constructive and multidimensional way offers researchers unusual departure points. This case may make the research an authentic, creative and qualified one. In educational research processes, researchers experience very valuable, beneficial data acquisition process through art-based approaches (Irwin \& O’Donoghue, 2012; Hickman, 2007). Different artistic ways of expression or forms can be used as tools for investigating their educational experiences in educational research process

\section{Reflections on Research Outcomes}

Art-based research approaches makes it highly possible to have unusual outcomes from researches as the research process is strictly structured. This case increases the quality 
significantly with regards to both participants and the people who are affected from research outcomes, and thus it gives the chance to adapt newer perspectives for future studies. The reflections of artistic forms and expressions on research process in art-based education researches can differ depending on the participants; because participants have the chance to put themselves in the researchers' place (Ellis, 2004). Thus, they can reflect their experiences and perspectives considering some extend of discipline and sensitivity.

\section{Conclusion}

The transformations and changes in research approaches nowadays have been restructuring research processes. Based on these transformations, it has become a necessity to question and structure research making competencies depending on both researchers, research perspective and the method and approach used. For the researchers of future to be qualified ones, it has become a necessity to adapt a multidimensional perspective in research process. The interpretations of research process through various disciplines and approaches depending on these disciplines will contribute to researchers' research process, and will make researchers more qualified and will help interpret research process through different alternatives. With this regard, the educational programs in which new research approaches and perspectives are effectively used, should be very careful with regards to their content and applications. In brief, it is an unavoidable reality that art-based research approaches will contribute a lot to researchers' competencies and vision formation. Considering this result, it can be suggested that adaptation of art-based educational research approach has become very significant when considered from multi-perspective approaches. 


\section{Reference}

Altheide, D. L., \& Johnson, J. M. (2011). Reflections on interpretive adequacy in qualitative research. N. K. Denzin, \& Y. S. Lincoln içinde (Eds.), The SAGE handbook of qualitative research (ss. 581-594). Thousand Oaks, CA: SAGE.

Alvesson, M. \& Skoldberg, K. (2000). Reflexive methodology: New vistas for qualitative research. London: Sage.

Badmington, N. (ed) (2000) Posthumanism. Basingstoke: Palgrave.

Barone, T. \& Eisner, E. W. (1997) Art-based educational research. R. M. Jaeger, (Ed.), Complementary methods for research in education içinde, (ss., 73-116).Washington DC. : American Educational Research Association Press.

Barone, T. (2008). How arts-based research can change minds. M. Cahnmann-Taylor \& R. Siegesmund (Eds.), Arts-based research in education: Foundations for practice içinde (ss. 28-49). New York: Routledge.

Barone, T., \& Eisner, E. W. (2012). Arts based research. Thousand Oaks, CA: Sage.

Boudreau, M., Gefen, D. \& Straub, D. (2001). Validation in is research: A state-of-the-art assessment, MIS Quarterly, (25) 1, 1-23.

Chalmers I, Altman D.G., (1995). Systematic reviews. London: BMJ Publishing Group.

Cahnmann-Taylor, M., \& Siegesmund, R. (Eds.) (2008). Arts-based research in education: Foundations for practice. New York, NY: Routledge.

Clark A and Percy-Smith B (2006). Beyond consultation: Participatory practices in everyday spaces, Children, Youth and Environments, 16 (2), 1-9. 
Cobb, P., Confrey, J., diSessa, A., Lehrer, R. and Schauble, L. (2003). Design experiments in educational research. Educational Researcher, 32(1), 9-13.

Cole, A. L. \& Knowles, J. G. (2001). Lives in context: The Art of life history research. Walnut Creek, CA: Alta Mira Press.

Collins, A., Joseph, D. and Bielaczyc, K. (2004). Design research: Theoretical and methodological issues. Journal of the Learning Sciences, 13(1), 15-42.

Cooper H. (1998). Synthesizing research: A guide for literature reviews. Thousand Oaks: Sage Publications.

Creswell, J. W. (2009) Research Design: Qualitative, Quantitative, and Mixed Methods Approaches, Sage, Thousand Oakes

Creswell, J. W., Plano Clark, V. L., Gutmann, M. L. and Hanson, W. E. (2003). Advanced mixed methods research designs. A.Tashakkori ve C. Teddlie (Ed.), Handbook of mixed methods in social and behavioral research içinde (s. 209-240). Thousand Oaks, CA: Sage.

Denzin N.K. \& Lincoln, Y. S.(2005). The Sage handbook of qualitative research. Thousand Oaks, CA: Sage Publications.

Diamond, C. T. P. \& Mullen, C. A. (Eds.), (1999). The postmodern educator: Arts-based inquiries and teacher development. Newyork: Peter Lang.

Dixon, M. \& Senior, K. (2010). Traversing theory and transgressing academic discourses: Artsbased research in teacher education, International Journal of Education and the Arts. 10(24). 
Eisner, E. W. (1997). The promise and perils of alternative forms of data representation. Educational Researcher, 22(7), 5-11.

Eisner, E. W. \& Barone, T. (1997). Art-based educational research. R. M. Jaeger (Ed.), Complementary methods for research in education içinde (ss. 73-79). AERA. Washington, DC.

Eisner, E. W. (2002). The arts and the creation of mind. New Haven, CT: Yale University Press.

Ellis, C. (2004). The Ethnographic I: A methodological novel about autoethnography. Walnut Creek, CA: AltaMira Press.

Finley, S. \& Knowles, J. G., (1995). Researcher as artist/ artist as researcher. Qualitative Inquiry, 1(1), 110-142.

Finley, S. (2005). Arts-based inquiry: Performing revolutionary pedagogy. N. K. Denzin, \& Y. S. Lincoln (Eds.). The Sage Handbook of Qualitative Research içinde (ss. 681-694).. Thousand Oaks, CA: Sage Publications.

Fraenkel, J., Wallen, N., \& Hyun, H.H. (2012). How to design and evaluate research in education (8. basim). Boston: McGraw Hill.

Hickman, R. (2007). Visual art as a vehicle for educational research. International Journal of Art \& Design Education, 26(3), 314-324.

Irwin, R. L. (2004). A/r/tography: A metonymic métissage. In Irwin, R. L. \& de Cosson, A. (Eds.). A/r/tography: Rendering self through arts based living inquiry içinde (ss. 27-38). Vancouver, BC: Pacific Educational Press. 
Anadolu Journal of Educational Sciences International, Art Education Special Issue, November 2015

Irwin, R. L. \& O Donoghue, D. (2012). Encountering pedagogy through relational art practices. International Journal of Art and Design Education, 31(3), 221-236.

Leavy, P. (2009) Method Meets Art: Arts-Based Research Practice. New York: The Guilford Press.Springgay,Irwin, et al, 2008;

Merriam, S. B. (1998). Qualitative research and case study applications in education. San Francisco: Jossey-Bass.

Muller, M.J. (2008). Participatory design: The third space in HCI. J. Jacko and A. Sears (Ed.) içinde, Human-computer interaction: Development process. Mahway, NJ, Erlbaum.

Onwuegbuzie, A. J., and Combs, J. P. (2010). Emergent data analysis techniques in mixed methods research: a synthesis. Abbas Tashakkori and Charles Teddlie (Ed.), Handbook of mixed methods in social and behavioral research (2. Bask1) içinde (s. 397-430). Thousand Oaks, CA: Sage.

Patton, M.Q. (1997). How to use qualitative methods in evaluation. Newbury park, CA: SAGE Publications.

Skivenes, M. \& Stranbu, A. (2006). A child perspective and children's participation, children, Youth and Environments, 16(2), p. 10-27.

Smith, Susan E. (1997). Participatory action-research within the global context. Susan Smith, Dennis B. Willms and Nancy A. Johnson (eds.) içinde (s. 1-6). Nurtured by Knowledge; Learning to do Participatory Action-Research. New York: Apex Press.

Sullivan, G. (2010). Art practice as research: Inquiry in visual arts (2nd ed.). Thousand Oaks CA: Sage. 
Anadolu Journal of Educational Sciences International, Art Education Special Issue, November 2015

Wang, F. and Hannafin, M.J. (2005). Design-based research and technology-enhanced learning environments. Educational Technology Research and Development, 53(4), 5-23.

Zaphiris, P. \& Constantinou, P. (2007). Using participatory design in the development of a language learning tool. Interactive Technology and Smart Education, 4(2), 79-90. 